\title{
INFERENTIAL MEASUREMENT OF SAG MILL PARAMETERS V: MPC SIMULATION
}

\author{
T. A. APELT ${ }^{* \S}$ and N. F. THORNHILL ${ }^{\S}$ \\ ${ }^{\S}$ Centre for Process Systems Engineering, Imperial College SW7 2BY. Email: thomasapelt@yahoo.com \\ * Department of Chemical Engineering, University of Sydney NSW 2006 \\ (Received ; accepted )
}

\begin{abstract}
This paper discusses a case study application of inferential measurement models for semiautogenous grinding (SAG) mills and is the last in a five-part series on Inferential Measurement of SAG Mill Parameters. Inferential measurements of SAG mill discharge and feed streams and mill rock and ball charge levels, detailed earlier in the series, are utilised in a simulation environment. A multi-variable, model predictive (MPC) controller simulation is developed from plant data and utilised to investigate the potential of utilising the inferential meodels in a mill charge control strategy. An operating curve is generated and discussed in terms of possible utilisation in conjunction with an MPC controller. The results are encouraging and potential avenues for further research are discussed.
\end{abstract}

\section{Keywords}

SAG milling; Mineral processing; Modelling; Simulation; Process control

\section{INTRODUCTION}

This paper describes a case study application of inferential models of the mill inventory and various streams in the primary grinding circuit and is a continuation of earlier work (Apelt et al., 2001a, Apelt et $a l ., 2002 a$, Apelt et al., 2002b; Apelt and Thornhill, In Press). The inferential measurement models developed in this research are placed into context by utilising them in a multivariable model predictive $(M P C)$ controller simulation developed for this express purpose.

After a brief circuit description, the Results and Discussion first looks at the development of transfer functions and rate-of change coefficients for a multi-variable, model predictive $(M P C)$ controller. The performance of the $M P C$ controller simulation is compared to the that of a simulated PID controller. A SAG mill operating curve is developed and projected into three dimensional space for visualisation. MPC controller actions are super-imposed and discussed in terms of moving the process from one set of conditions to another. Translating the simulation study results to the real plant is an avenue for future research.

\section{CIRCUIT DESCRIPTION}

The discussion centres on the primary grinding circuit shown in Figure 1 which also shows process measurements relevant to this work. The abbreviations indicate the available process measurements for mass flowrate $(T P H)[\mathrm{t} / \mathrm{hr}]$, volumetric flowrate $(C M P H)\left[\mathrm{m}^{3} / \mathrm{hr}\right]$, stream density $(\%$ sols $)$ [\% solids w/w], 
mill powerdraw $k W[\mathrm{~kW}$ ], and mill load cell weight $L C$ [t]. This example of a grinding circuit would be considered well insturmented according to the guidelines defined by Fuenzalida et al. (1996). The available measurements are as follows:

- $\quad$ SAG mill fresh (stockpile) feed $[\mathrm{t} / \mathrm{hr}]$

- $\quad$ SAG mill feed water addition $\left[\mathrm{m}^{3} / \mathrm{hr}\right]$

- $\quad$ SAG mill powerdraw $[\mathrm{kW}]$

- $\quad$ SAG mill load cell [t]
- Cyclone feed water addition $\left[\mathrm{m}^{3} / \mathrm{hr}\right]$

- Cyclone feedrate $\left[\mathrm{m}^{3} / \mathrm{hr}\right]$

- Cyclone feed density [\% solids $\mathrm{w} / \mathrm{w}]$

- Oversize crusher feedrate $[\mathrm{t} / \mathrm{hr}]$

Ore is fed to the SAG mill for primary grinding. The mill discharge is screened with the oversizedmate rial recycling via a gyratory cone crusher, and the screen undersize being diluted with water and fed to the primary cyclones for classification. Primary cyclone underflow is split between a small recycle stream to the SAG mill feedchute and a ball mill feed stream. The primary grinding circuit products are subjected to further size reduction (ball mill), classification (cyclones) and separation (flash flotation) in the secondary grinding circuit. Further details of the grinding circuit and the other sections of the processing plant may be found elsewhere (Apelt et al., 2001a,b; Freeman et al., 2000; Apelt, 2007).

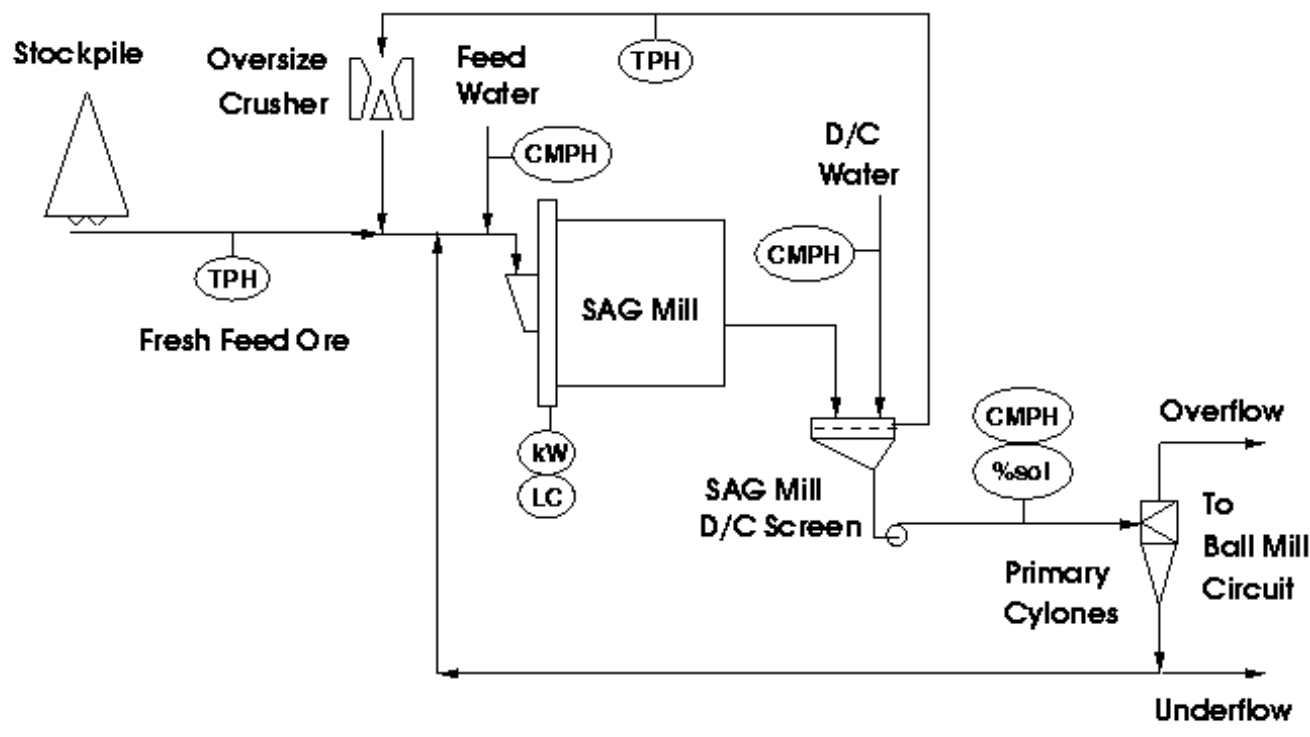

Fig.1 Primary grinding circuit process flowsheet

\section{INFERENTIAL MEASUREMENT MODEL SUMMARY}

This section recapitulates the inferential rmeasurement models relevant to this paper. Model details are found elsewhere (Apelt et al., 2002b; Apelt, 2007, Apelt and Thornhill., In Press).

\section{Model Overview}

The Inferential measurement models of the SAG mill inventories, feed rate and sizing and mill discharge rate and sizing requires are determined in the following six-step sequence:

1. Oversize crusher feed, primary cyclone feed, SAG mill discharge, including the transfer sizes $\left(T_{80} \ldots T_{20}\right)$ 
2. SAG mill rock charge;

3. SAG mill fractional total filling, $J_{t}$, fractional ball filling, $J_{b}$, and fractional rock charge filling, $J_{r},\left(J_{r}=J_{t}-J_{b}\right)$;

4. SAG mill total feed;

5. Oversize crusher product and primary cyclone underflow; and,

6. SAG mill fresh feed, including the feed sizes $\left(F_{80} \ldots F_{20}\right)$.

\section{RESULTS AND DISCUSSION}

\section{Model Predictive Controller Simulation}

To place the utilisation of the inferential measurement models into context, a multi-variable, model predictive controller $(M P C)$ controller simulation was developed using transfer functions generated from plant data. The simulation was conducted using Connoisseur, the model-predictive control package of the process control hardware and software company Invensys.

The interactions between variables in primary and secondary milling circuits, real and simulated, may be characterised by transfer functions (Radhakrishnan, 1999; Freeman et al., 2000; Ivezič and Petrovič, 2003; Ramasamy et al., 2005; Chen et al., 2007; Apelt, 2007). The plant data and inferential measurement model results, discussed in the previous paper (Apelt and Thornhill, In Press), were analysed to determine estimates for the interactions between key variables. Each process interaction was approximated by a firstorder plus time-delay transfer $(F O P T D)$ function. Such an approximation is satisfactory for process variables that are not integrating by nature, such as tank levels. The approximation can successfully be applied in real-plant situation, as seen in Freeman et al. (2000).

A matrix of ten (10) controlled variables $(C V s)$ by five (5) manipulated variables $(M V s)$ and Feed-forward variables $(F V s)$, i.e., $10 \times 5$, defines the controller structure. The plant transfer function resulting from the analysis of the plant interactions are contained in Table 1.

Experimention with a simulation based on these FOPTD models gave unsatisfactory (unrealistic) results. The simulation was predicting the asymptotic approach to a new steady-state process value (characteristic of a FOPTD model) for the rock charge, regardless of the starting conditions. For certain conditions this would occur but not across the full range of possible conditions. For example, for high rock (and total) charge levels and a constant moderate ball charge level, an increase in feedrate would cause the mill to overload (from rock charge integration). The FOPTD transfer function does not capture changing breakage rates (for the rock contents) and changing wear rates (for the grinding charge contents) for different operating conditions. Since the different operating conditions cause different behaviour in the SAG mill charge levels, the FOPTD approximation is not satisfactory.

Therefore, the SAG mill was modelled as an integrator for rock and grinding media. The in-flows are the mill feed and the ball addition rate. The out-flows are the rock charge breakage and the ball charge wear. An isolated increase in either the feedrate or the ball addition rate will cause either the rock charge or ball charge, respectively, to increase monotonically until mill over-load. (This is effectively true for the ball charge but only an approximation for the rock charge.) The asymptotic approach to a new steady-state process value, characteristic of a FOPTD transfer function, will not eventuate for the ball charge and rarely for the rock charge. 
TABLE 1 Plant Transfer Functions

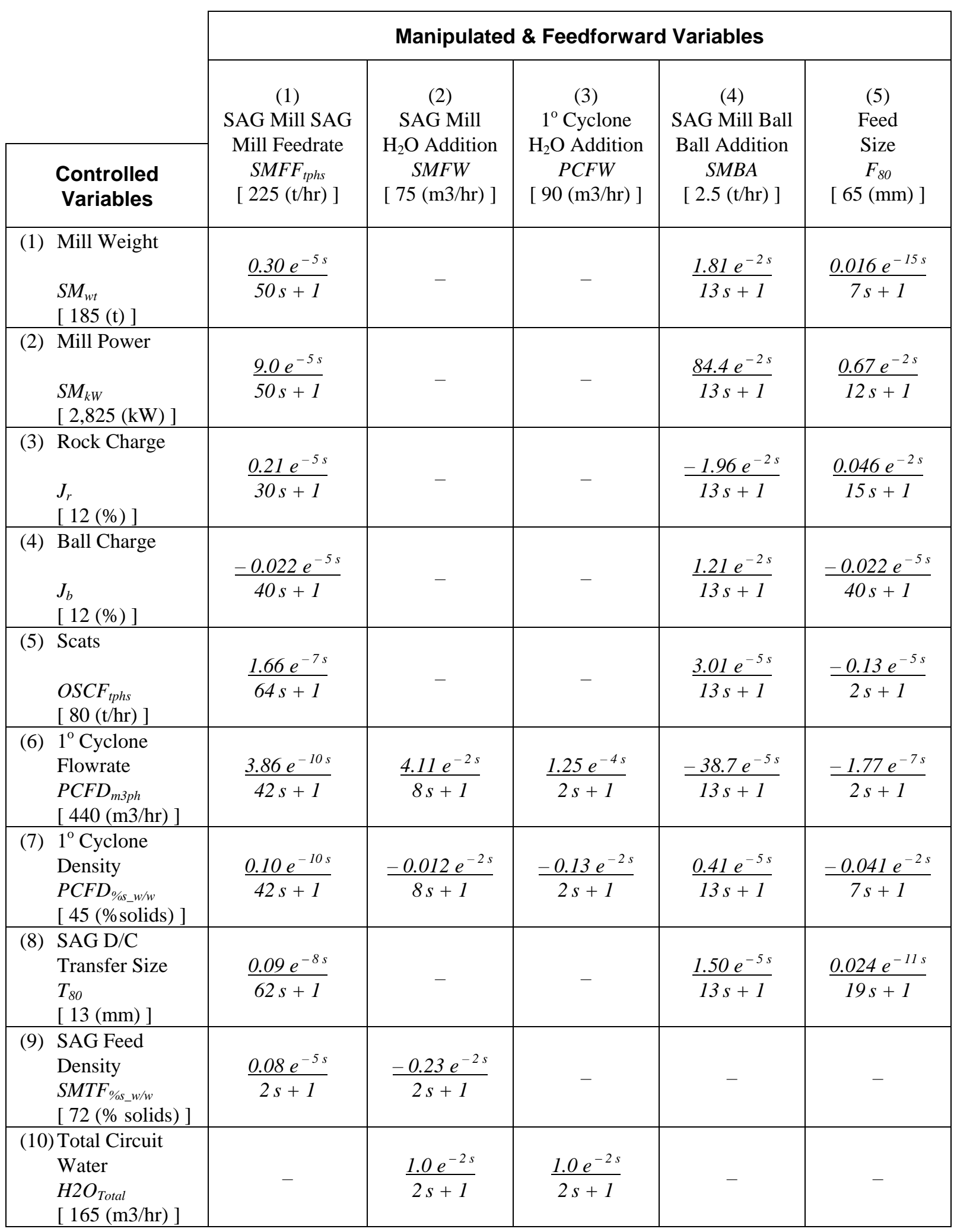


To address this issue, the $C V \mathrm{~s}$ in Table 2 that relate to the integrating nature of the SAG mill, namely, the mill weight, powerdraw, rock charge and ball charge, were modelled as integrators. In the Connoisseur environment, integrators are modelled by way of rate-of-change $(R O C)$ models. The $R O C$ coefficients are calculated using as follows:

$$
\text { ROC }_{C V}=\frac{\text { Range }_{C V}}{\text { Volume }_{\text {Vessel }}} * \frac{P I}{\text { Time Conversion }} * \Delta M V
$$

where $R O C_{C V}$ is the rate of change of the $C V$ [CV units per $\left.P I\right], P I$ is the prediction interval [time units], Range $_{C V}$ is the $C V$ range over the vessel volume [ $C V$ units], Time Conversion is a conversion factor for $M V$ time units to $P I$ units [time over time] and $\triangle M V$ is the change in the MV that causes the change in $C V[M V$ units].

Table 2 contains the $R O C$ coefficients utilised in this simulation. The coefficients were either calculated from first principles or from the plant data and results presented in the previous paper (Apelt and Thornhill, In Press). For example, ball addition, SMBA (t/hr) can be translated into a volumetric rate based on ball specific gravity and voidage, which can in turn be translated into a ball charge change based on the mill dimensions; a first principles determination.

The $R O C$ coefficient for ball addition $(S M B A)$ to rock charge $\left(J_{r}\right)$, on the other hand, is derived from the data. An increase in the ball charge level causes a decrease in the rock charge level, observed from the data. The increase in ball charge level may be translated to a ball addition rate, by the reverse procedure of the previous example.

TABLE 2 Rate of Change Model Coefficients

\begin{tabular}{|l|l|l|}
\hline Relationship & ROC & Notes \\
\hline$\left(\right.$ a) $S M F F \rightarrow S M_{w t}$ & $0.025(\mathrm{t} / \mathrm{min})$ & Accumulating rock charge increases mill weight \\
\hline (b) $S M F F \rightarrow S M_{k W}$ & $0.782(\mathrm{~kW} / \mathrm{min})$ & Accumulating rock charge increases mill powerdraw \\
\hline (c) $S M F F \rightarrow J_{r}$ & $0.037(\% / \mathrm{min})$ & Extra feedrate increases rock charge \\
\hline (d) $S M F F \rightarrow J_{b}$ & $-8 \times 10^{-6}(\% / \mathrm{min})$ & Ball charge wear caused by extra feedrate \\
\hline (e) $S M B A \rightarrow S M_{w t}$ & $0.024(\mathrm{t} / \mathrm{min})$ & $\begin{array}{l}\text { Extra ball addition increases mill weight (increased ball charge } \\
\text { and rock charge reduction) }\end{array}$ \\
\hline (f) $S M B A \rightarrow S M_{k W}$ & $2.606(\mathrm{~kW} / \mathrm{min})$ & Accumulating ball charge increases powerdraw \\
\hline (g) $S M B A \rightarrow J_{r}$ & $-0.312(\% / \mathrm{min})$ & Rock charge breakage due to Increasing ball charge \\
\hline (h) $S M B A \rightarrow J_{b}$ & $0.013(\% / \mathrm{min})$ & Extra ball addition increases ball charge \\
\hline (i) $F_{80} \rightarrow S M_{w t}$ & $0.025(\mathrm{t} / \mathrm{min})$ & Larger (harder) feed rocks increase rock charge and mill weight \\
\hline (j) $F_{80} \rightarrow S M_{k W}$ & $0.719(\mathrm{~kW} / \mathrm{min})$ & Increased rock charge causes powerdraw increases \\
\hline (k) $F_{80} \rightarrow J_{r}$ & $0.037(\% / \mathrm{min})$ & Larger (harder) feed rocks increase rock charge \\
\hline (l) $F_{80} \rightarrow J_{b}$ & $-8 \times 10^{-6}(\% / \mathrm{min})$ & Ball charge wear caused by increased rock charge \\
\hline
\end{tabular}

Utilising the transfer functions and $R O C$ coefficients in Tables 1 and 2, respectively, the development of a model predictive controller (MPC) was progressed according to the structure shown in Figure 2 


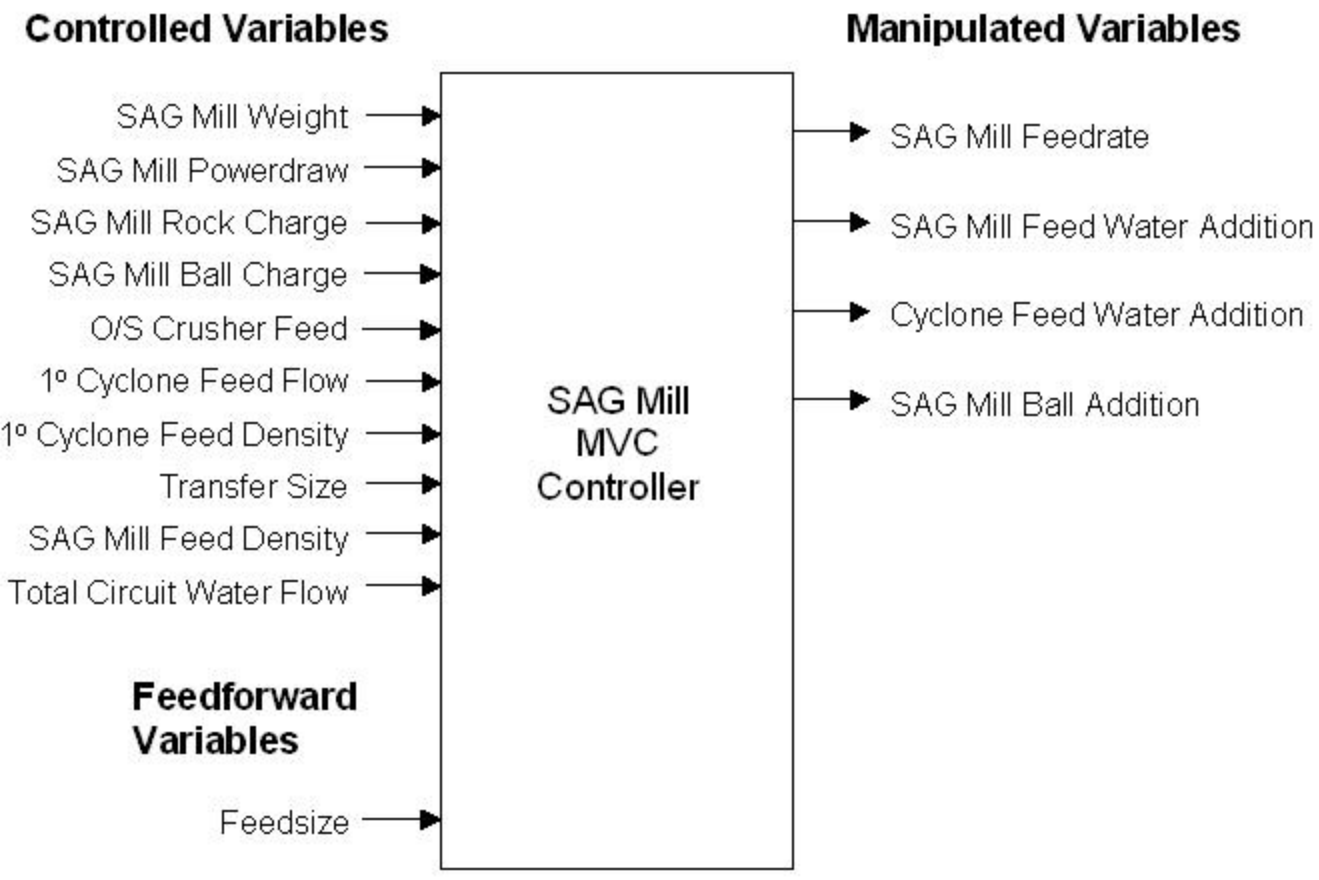

Fig.2 Model predictive controller structure with $10 \mathrm{x} C V$ s by $4 \mathrm{x} M V$ s and $1 \mathrm{x} F V(10 \times 5)$.

For the purpose of $M P C$ controller performance assessment, a simulation PID controller was also developed. The structure of the PID controller is shown in Figure 3. The PID controller manipulates the SAG mill feedrate to control the mill powerdraw.

\section{Controlled Variables \\ Manipulated Variables}

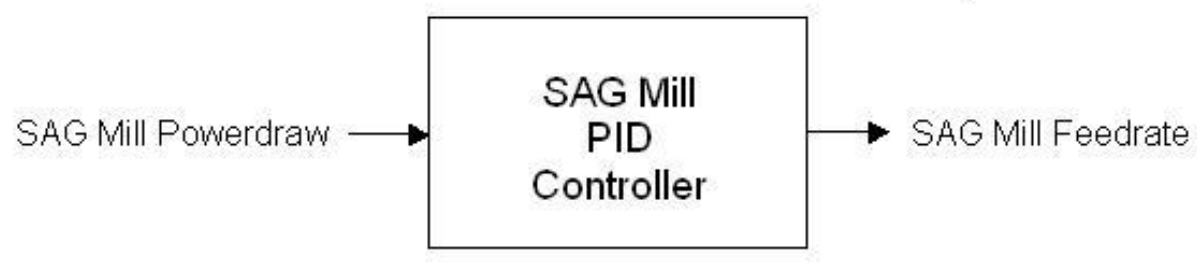

Fig.3 Simulated PID controller structure. A SISO (single input, single output) controller with one $C V$ and one $M V$.

The simulation study comprised the introduction of a disturbance in the feed size $\left(F_{80}\right)$, which can occur in its own right but is usually associated with a disturbance in the ore hardness. Generally, the harder the ore, the more coarse the feed ore and thus, the larger the $F_{80}$.

The feedsize $F_{80}$ (Feedfoward Variable) was stepped up ten (10) times from $65 \mathrm{~mm}$ to $70 \mathrm{~mm}$. The 
elevated $F_{80}$ is held for a period before the disturbance is reversed, returning the $F_{80}$ to its original level. The model predictive controller was configured to utilise the inferential measurement models developed in this research. The ball charge $\left(J_{b}\right)$ and rock charge $\left(J_{r}\right)$ were specified to be setpoint controlled $C V$ s. The transfer size $\left(T_{80}\right)$ was specified as a constraint-controlled $C V$. That is, the MPC controller would let its value move freely between specified high and low limits. The remaining $C V$ s were also specified as constraint-controlled $C V \mathrm{~s}$ with various priority levels, refer to Table 3.

TABLE 3 MPC Controlled Variable Classification

\begin{tabular}{|l|l|}
\hline Setpoint-Controlled Variables & Constraint-Controlled Variables \\
\hline Ball Charge, $J_{b}$ & Transfer Size, $\mathrm{T}_{80}$ \\
\hline Rock Charge, $\mathrm{J}_{\mathrm{r}}$ & Powerdraw, $\mathrm{SM}_{k W}$ \\
\hline & All remaining (6) CVs \\
\hline
\end{tabular}

This configuration ensured that the controller was not over-specified and had the flexibility to achieve the control objectives. Due to obvious impact the violation of the high constraint would have, the constraintcontrol of the powerdraw was given the highest priority. Adherence to the ball charge setpoint was given the same priority. The rock charge setpoint and the other constraint-controlled variables were assigned lower priorities.

The movements made to the feedrate $M V$ are shown in Figure 4. The behaviour of the $M P C$ and $P I D$ controllers are not markedly different. The PID controller moves the feedrate before the the $M P C$ and has an overshoot-with-trim type of shape.

Powerdraw is a constraint-controlled variable in the $M P C$, while it is the $C V$ for the $P I D$ loop. The closedloop behaviour is shown in Figure 5. The PID controller does not hold the powerdraw as tightly to the setpoint of $2,825 \mathrm{~kW}$ as the model predictive controller. The powerdraw is a constraint-controlled $C V$ in the $M P C$ controller and is set with a high priority. Hence, the powerdraw being held at $2,825 \mathrm{~kW}$ is a consequence of the high priority placed on the observance of the powerdraw constraints and the controller trying to achieve the other control objectives, such as ball charge setpoint control.

Inspection of Figure 5 reveals that the performance of both the $M P C$ and $P I D$ controllers are very good. It should be noted that good controller performance is to be expected since it is a simulation. Generally, the performance of model-predictive (multi-variable) controller was found to be superior to that of the PID controller. However, since the PID controller is the perfect PID controller (it was modelled, tuned and implemented in Connoisseur), the performance difference was found to be slight. The difference would be magnified in a real-plant application

The open and closed-loop manipulation of the ball addition rate is shown in Figure 6. Since, there is no manipulation of the ball addition rate in the PID-controlled and open-loop scenarios, the ball addition rate is a constant $2.5 \mathrm{t} / \mathrm{hr}$ in these cases. Figure 7 illustrates the open and closed-loop behaviour of the SAG mill ball charge. The PID-controlled response is essentially constant, lying virtually concurrent with the $12.0 \%$ grid-line. The high level of setpoint control achieved by the MPC controller here $\approx \pm 0.005 \%$, compared to the setpoint control of the rock charge, see Figure 8 , is on account of the higher priority placed on the ball charge setpoint control.

Figure 8 shows the open-loop and closed-loop behaviour of the rock charge, which is maintained between $\approx \pm 0.2 \%$ from setpoint. The PID controller is actually controlling powerdraw not weight. However, as both variables are highly correlated, controlling powerdraw brings millweight under a degree of control. 


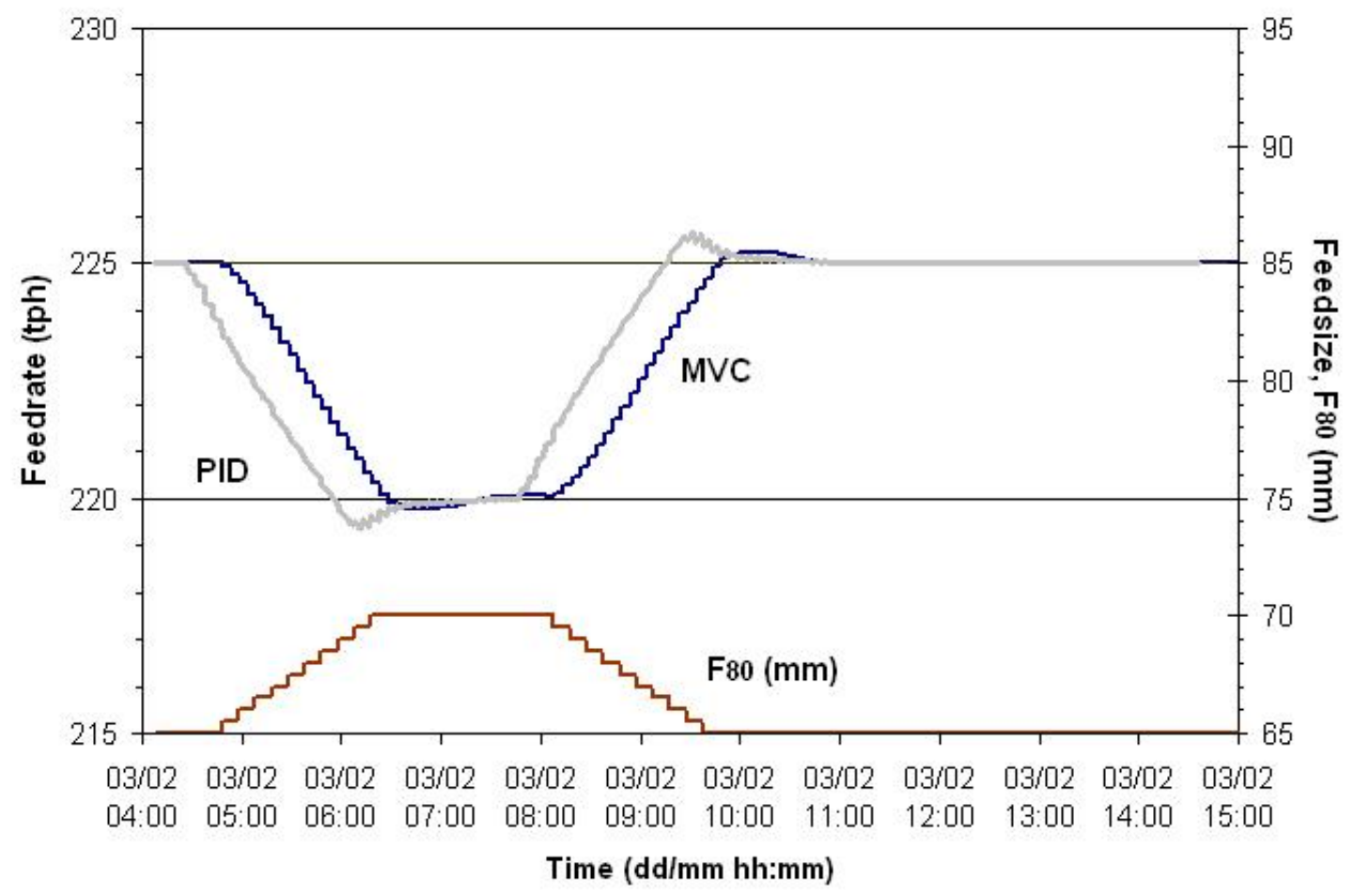

Fig.4 Simulated plant results showing feedsize $F_{80}$ disturbance and closed-loop feedrate manipulations of the PID and $M V C$ controllers.

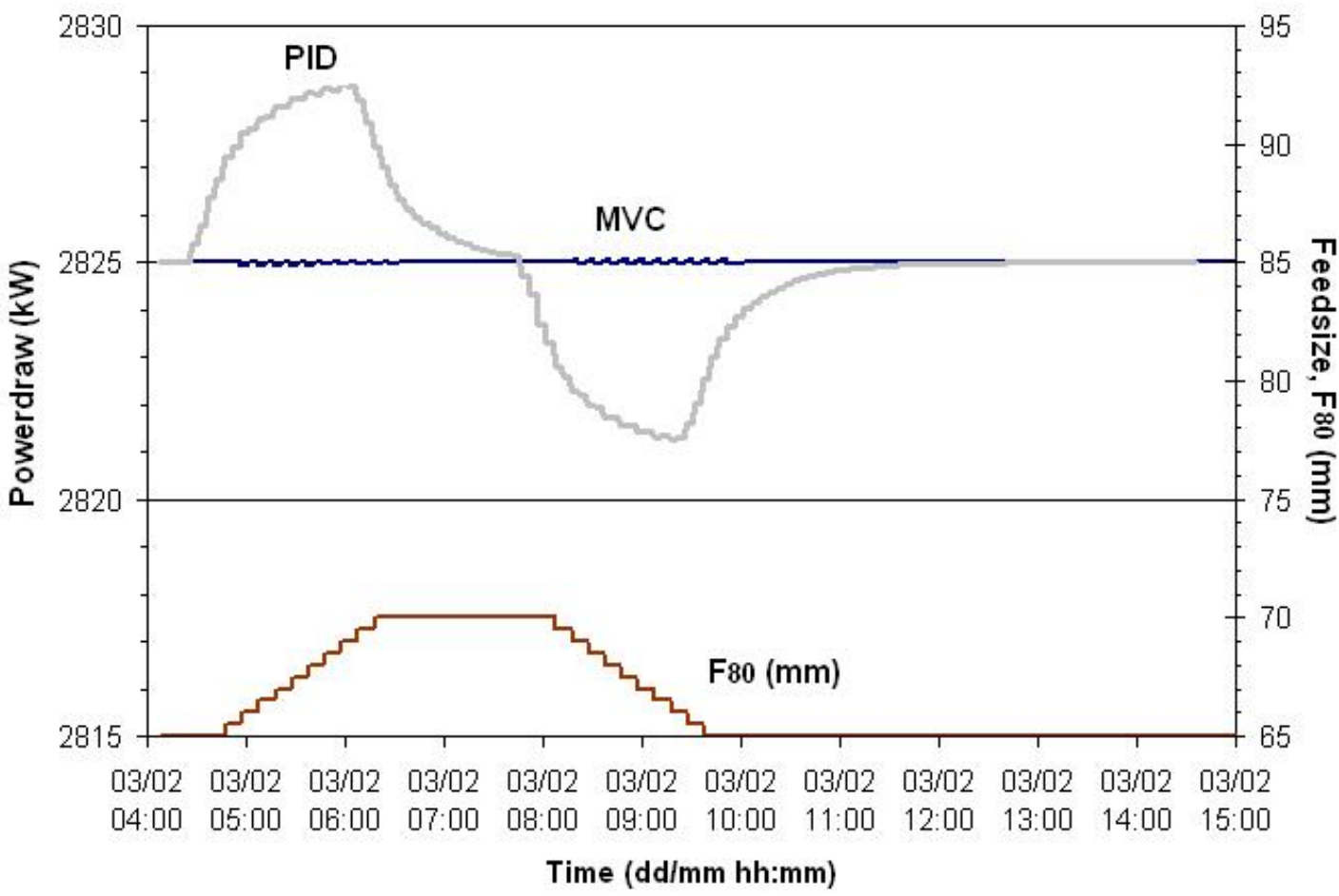

Fig.5 Simulated plant results showing feedsize $F_{80}$ disturbance and closed-loop response of the SAG mill powerdraw. 


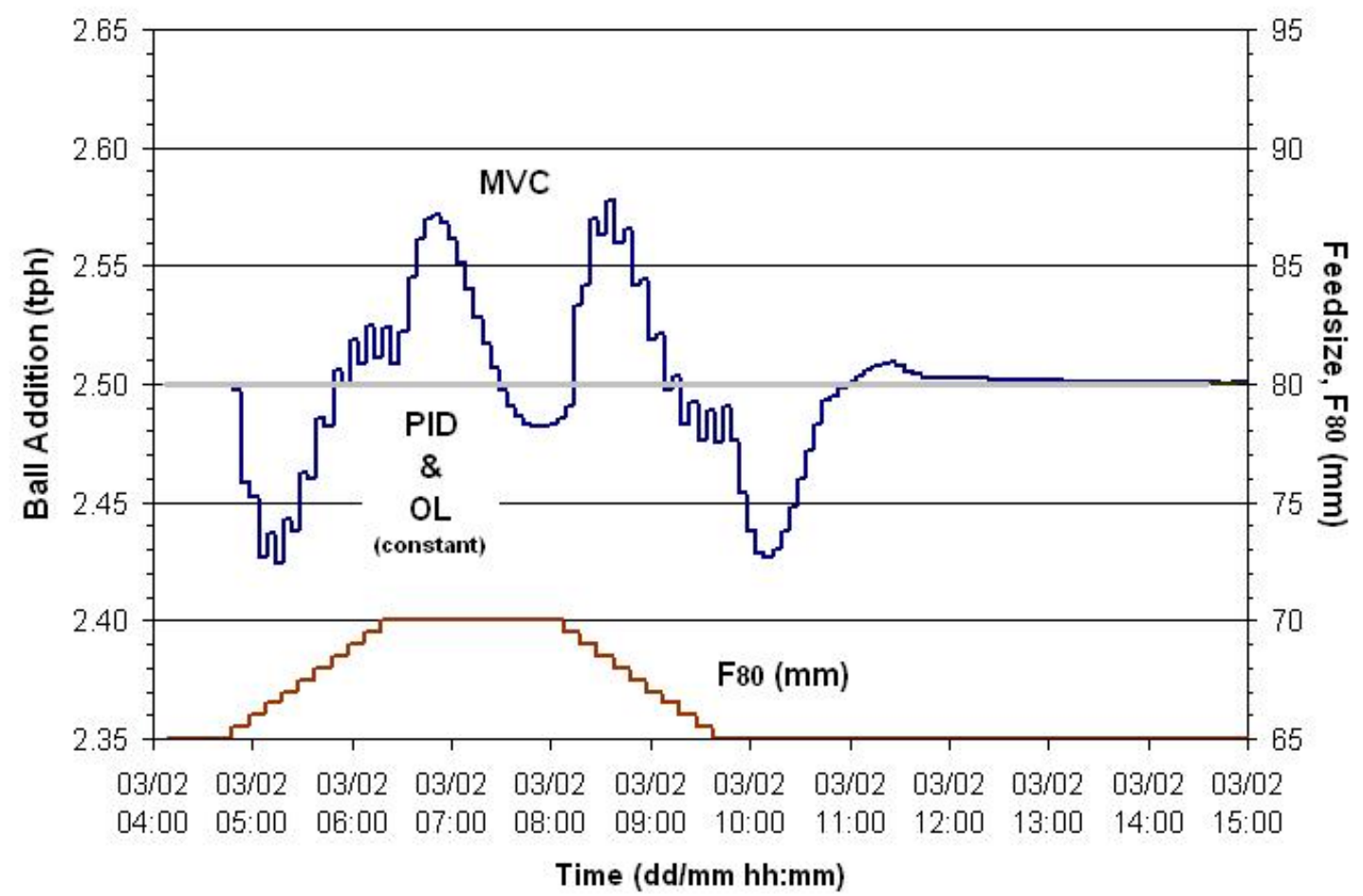

Fig.6 Simulated plant results showing feedsize $F_{80}$ disturbance and closed-loop ball addition manipulations MVC controller. No controller actions for open loop (OL) and PID control cases.

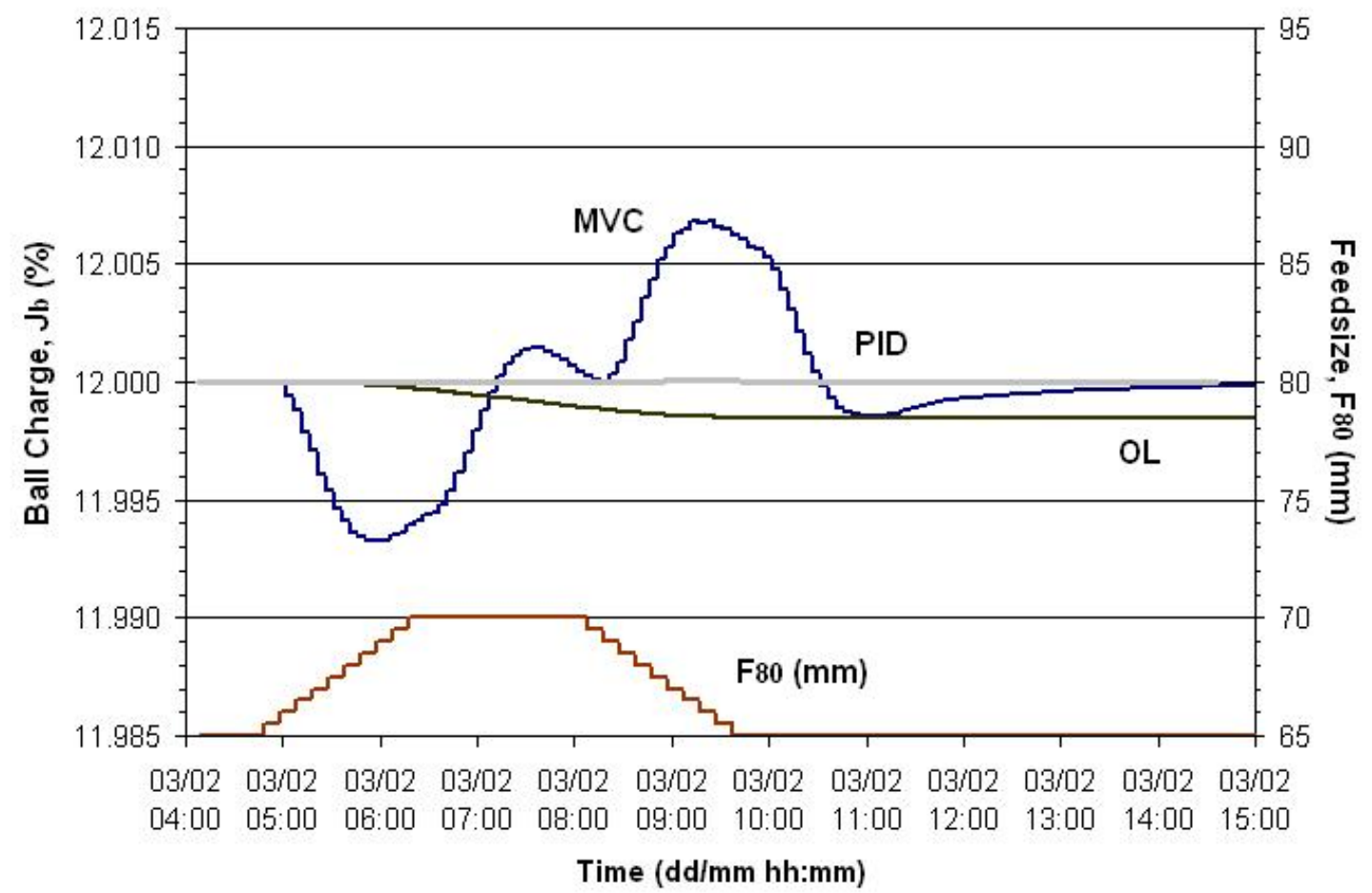

Fig.7 Simulated plant results showing feedsize $F_{80}$ disturbance and open and closed-loop response of SAG mill ball charge fraction $\left(J_{b}\right)$. PID response virtually concurrent with $12.0 \%$ ball charge. 


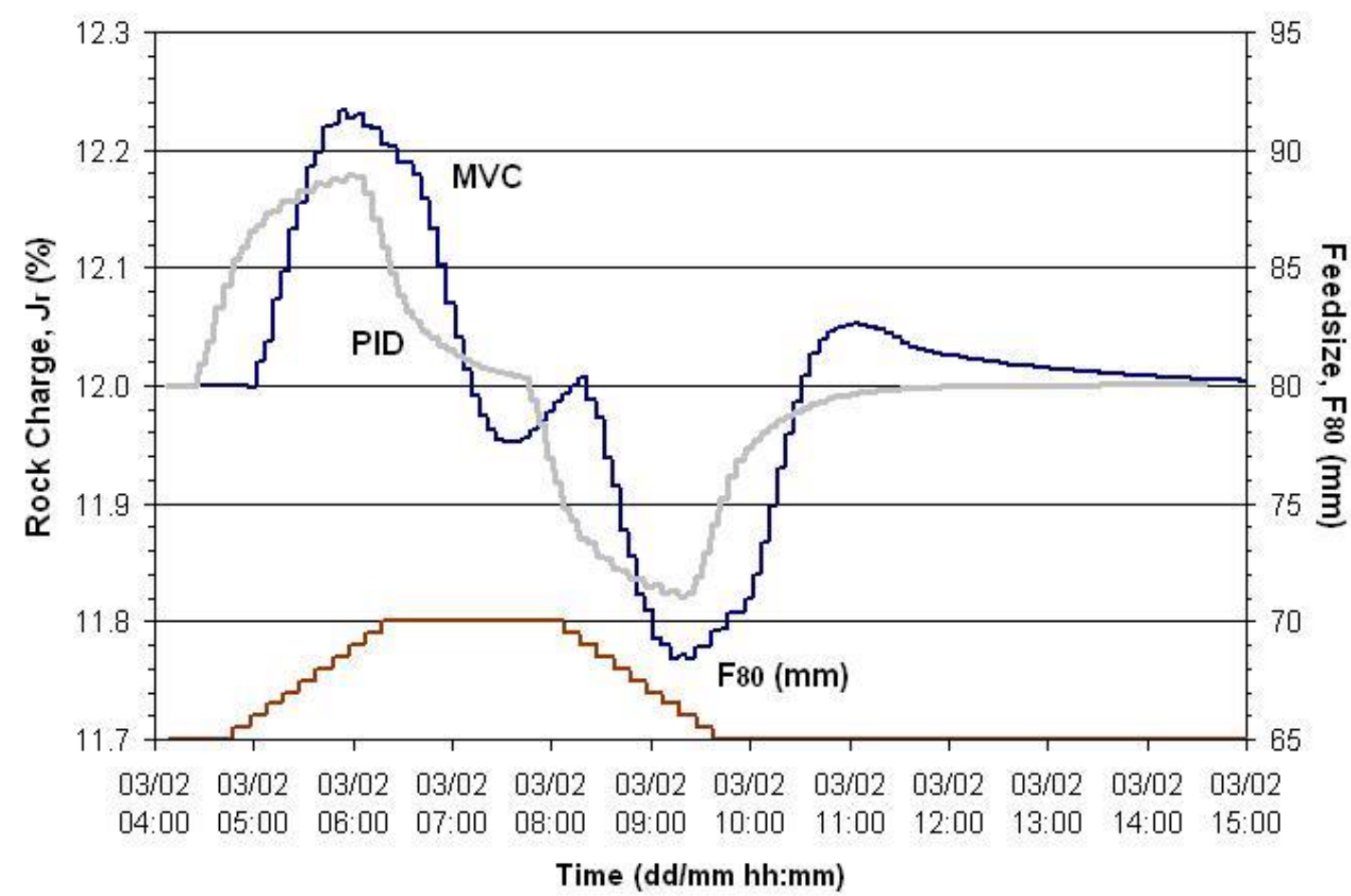

Fig.8 Simulated plant results showing feedsize $F_{80}$ disturbance and open closed-loop response of SAG mill rock charge fraction $\left(J_{r}\right)$.

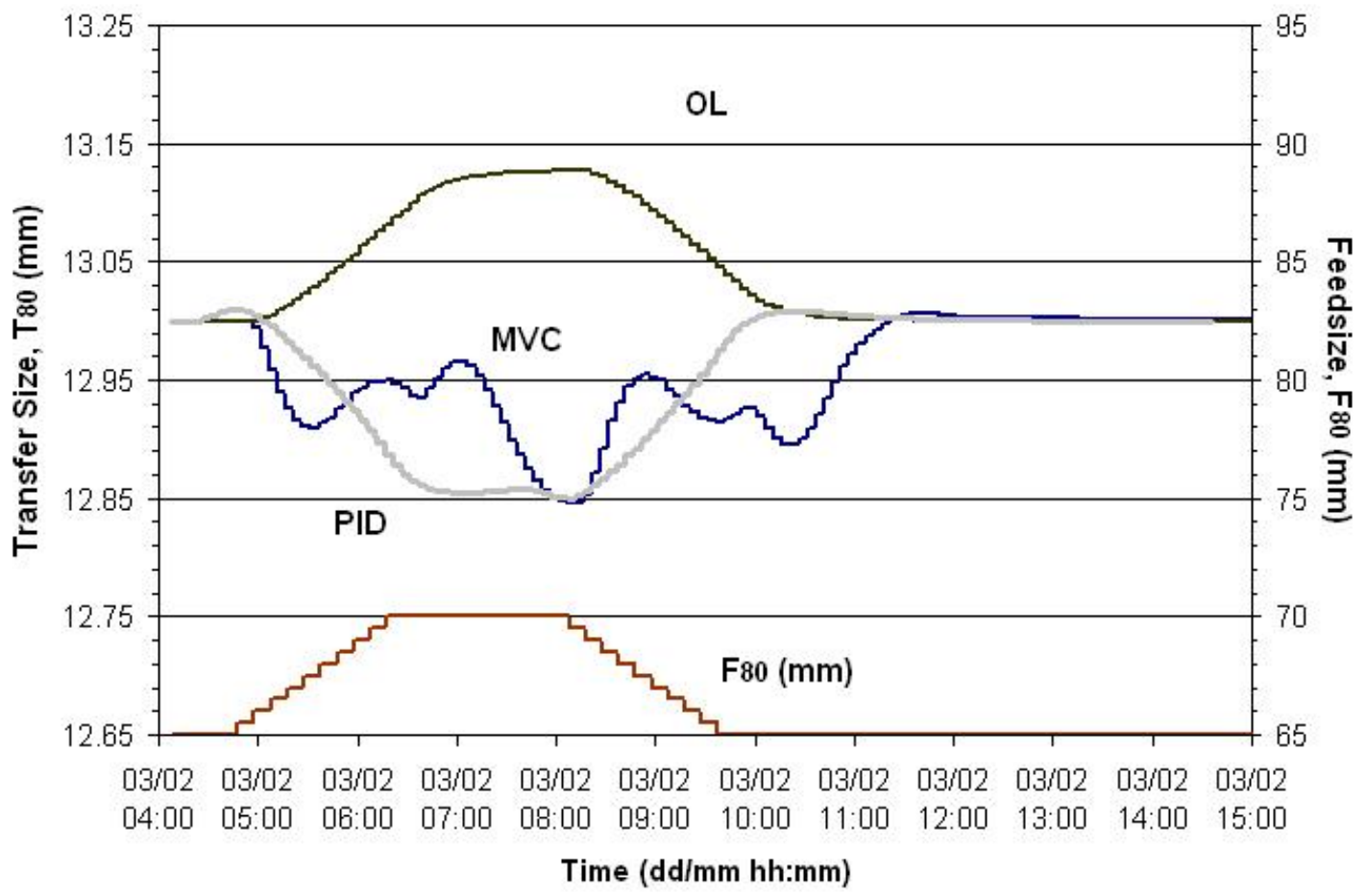

Fig.9 Simulated plant results showing feedsize $F_{80}$ disturbance and open and closed-loop response of SAG mill transfer size $\left(T_{80}\right)$. 
Figure 9 shows the open and closed-loop behaviour of the transfer size, $T_{80}$. Neither of the closed-loop controllers attempt to control the transfer size to a setpoint. The MPC controller does, however, control the transfer size within the low $(11 \mathrm{~mm})$ and high $(13 \mathrm{~mm})$ constraints. Applied in a real-plant application, the ability to control the transfer size with a size range could be useful in balancing the loading on the primary and secondary circuits.

Overall, the performance of multi-variable $M P C$ controller was found to be superior to that of the PID controller. However, since the PID controller is the perfect PID controller (it was modelled, tuned and implemented in Connoisseur), the performance difference was found to be slight. The difference would be magnified in a real-plant application and the application of MPC should result in a $1-2 \%$ increase in production. Near today's prices (approximately US\$3.50/lb), the economic benefit would be of the order of US\$1 million per annum for Module 1 grinding train at Northparkes Mines. Further results presentation may be found elsewhere (Apelt, 2007).

The preceding discussion has illustrated how the inferential measurement models developed in this research could be incorporated in an advanced process control structure for setpoint and constraint-control.

Further investigation of the use of the proposed model-predictive controller in conjunction with an optimiser, which would set the process setpoints based on certain economic criteria and the investigation of other controller configurations could further research in this area.

\section{SAG Mill Operating Curve}

The charge estimate contours presented in the previous paper (Apelt and Thornhill, In Press) and MPC control-action contours may be superimposed on the same total charge - ball charge region, to visualise the effects of controller action on the mill charge fractions. The control-action contours may be obtained from the controller rate-of-change $(R O C)$ coefficients. The $R O C$ coefficients are listed in full in Table 2. For ease of reference, the relevant $R O C$ coefficients are shown here in Table 4. Since the total charge is the addition of the rock and ball charges, the $R O C$ coefficient for a given manipulated variable is calculated from the addition of the $R O C$ coefficients for ball charge and rock charge.

TABLE 4 Rate of Change Coeffcients and Control Action Contour Slopes

\begin{tabular}{|c|c|c|c|c|}
\hline \multirow[b]{2}{*}{$\begin{array}{c}\text { Manipulated } \\
\text { Variable }\end{array}$} & \multicolumn{3}{|c|}{ Control Variables } & \multirow{2}{*}{$\begin{array}{l}\text { Control-Action } \\
\text { Contour, } \frac{\Delta J_{t}}{\Delta J_{b}} \\
\text { Slope }\end{array}$} \\
\hline & $\begin{array}{c}\text { Ball } \\
\text { Charge, } J_{b}\end{array}$ & $\begin{array}{c}\text { Rock } \\
\text { Charge, } J_{r}\end{array}$ & $\begin{array}{c}\text { Total } \\
\text { Charge, } J_{t}\end{array}$ & \\
\hline Feedrate, SMFF & $-8 \times 10^{-6}$ & 0.037 & 0.037 & -4906 \\
\hline Ball Addition, SMBA & 0.013 & -0.312 & -0.299 & -23.5 \\
\hline
\end{tabular}

The feedrate and ball addition are the two manipulated variables $(M V s)$ that affect the mill charge fractions. Control-action contours for each of the $M V s$ can be calculated from the ROC coeffcients. For feedrate, if we assume the ball addition remains constant, then the slope of control-action contours for feedrate in the total charge - ball charge space is calculated by dividing the total charge ROC coefficient by that of the ball charge. As long as the units for the ROC coefficients are consistent, the actual units are not crucial because they cancel out. By assuming feedrate remains constant, the control-action contour slopes for ball addition may be calculated similarly.

The control-action contours may be super-imposed on the total charge fraction versus ball charge fraction plots, see Figure 10, which are discussed in the previous paper (Apelt and Thornhill, In Press). The nearvertical (slope: -4906) line is a feederate contour. Feedrate changes have little effect on ball charge but a large effect on rock charge and, therefore, total charge. 


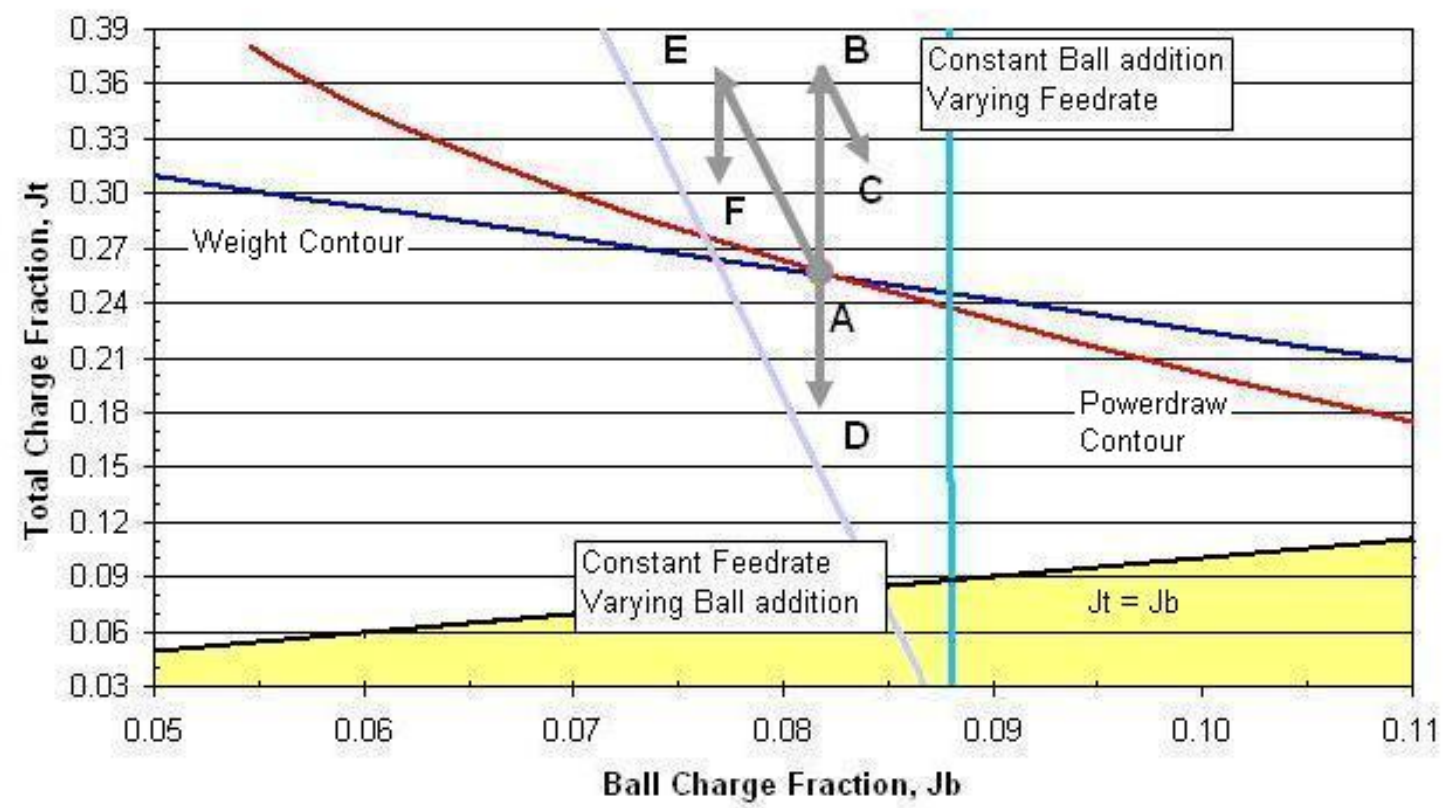

Fig.10 Control-Action Contours super-imposed on the reference mill powerdraw and weight contours. Feedrate control-action contour near-vertical (slope: -4906). Ball addition control- action contour has slope -23.5. Movements A - F explained in Table 5.

The other steep line (slope: -23.5) in Figure 10 is a ball addition contour. Ball addition changes clearly affect the ball charge. They also affect the total charge because the ball charge affects the rock charge. For example, increasing the ball addition, increases the ball charge, which decreases the total charge because it decreases the rock charge through breakage. Note that this contour has been placed to show the slope of the contour on the plot. The contour should not extend below the $J_{t}=J_{b}$ line, as it does in this diagram.

Also shown in Figure 10 is a number of arrows connecting points labeled A - F. These can be considered as controller moves, as detailed in Table 5. For example, increasing the ball charge and total charge (moving from $\mathrm{A}-\mathrm{C}$ ), is achieved through two control moves. Firstly, an increase in feedrate increases the total charge (by increasing the rock charge) with a near-zero decrease in ball charge (moving from $\mathrm{A}-\mathrm{B}$ ). Secondly, an increase in ball addition increases the ball charge with a decrease in total charge due to increased breakage of the rock charge (moving from B $-\mathrm{C}$ ). The overall result is an increased ball charge and an increased rock charge (with an increase in mill weight and an increase in powerdraw).

Perhaps for small control actions, the powerdraw and weight could be considered constant. However, for larger contoller moves, which affect the mill powerdraw and weight significantly, the powerdraw and weight contours will change accordingly.

Plotting the control moves in the two-dimensional charge fraction space $\left(J_{b}, J_{t}\right)$ and describing what is happening to the powerdraw and weight is not ideal for visualisation of what is occurring. The fourdimensional space may be reduced to a three-dimensional space by multiplying the prevalent powerdraw and weight signals together for each ball charge fraction, total charge fraction pairing $\left(J_{b}, J_{t}\right)$. The powerdraw and weight contours may be expanded into the three-dimensional space by mutiplying these by the prevailing weight or powerdraw. 
TABLE 5: Controller Moves in Jt - Jb for Figure 24

\begin{tabular}{|l|l|}
\hline Moves & Notes \\
\hline $\mathrm{A} \rightarrow \mathrm{B} \rightarrow \mathrm{C}$ & $\begin{array}{l}\text { Objective: Increase ball charge and total charge } \\
\text { Controller moves: Increase feedrate }(\mathrm{A} \rightarrow \mathrm{B}) \text { and Increase ball addition }(\mathrm{B} \rightarrow \mathrm{C}) \\
\text { Powerdraw-weight: Increased powerdraw - Increased Weight }\end{array}$ \\
\hline $\mathrm{A} \rightarrow \mathrm{D}$ & $\begin{array}{l}\text { Objective: Decrease total charge (rock charge) while maintaining ball charge } \\
\text { Controller moves: Decrease feedrate } \\
\text { Powerdraw-weight: Decreased powerdraw }- \text { Decreased weight }\end{array}$ \\
\hline $\mathrm{A} \rightarrow \mathrm{E} \rightarrow \mathrm{F}$ & $\begin{array}{l}\text { Objective: Increase total charge and decrease ball charge } \\
\text { Controller moves: Decrease ball addition }(\mathrm{A} \rightarrow \text { E) and Decrease feedrate }(\mathrm{E} \rightarrow \mathrm{F}) \\
\text { Powerdraw-weight: Increased powerdraw }- \text { Increased }\end{array}$ \\
\hline
\end{tabular}

Three sets of operating conditions were selected from plant data that were close together in time (for ore hardness consistency), display a trend and span a range of conditions (beneficial for plotting clarity), see Table 6. To fully investigate the hypothesis that the operating curve is dependent on ore hardness is not feasible here and was outside the scope of this research. However, it could be the topic of future research. The Logsheet and Shift Communication Book entries for Afternoon Shift 11 October 1997 onwards certainly support an ore hardness change, as the feed tonnage is backed off by $35 \mathrm{t} / \mathrm{hr}$ and feeders start hanging up, see Appendix D in Apelt (2007).

TABLE 6: Mill Operating Conditions for Operating Curve

\begin{tabular}{|c|c|c|c|c|c|}
\hline Time & $\begin{array}{c}\text { Weight } \\
\mathbf{( t )}\end{array}$ & $\begin{array}{c}\text { Powerdraw } \\
\mathbf{( k W )}\end{array}$ & $\begin{array}{c}\text { Total Charge } \\
\boldsymbol{J}_{\boldsymbol{t}} \text { (fraction) }\end{array}$ & $\begin{array}{c}\text { Ball Charge } \\
\boldsymbol{J}_{\boldsymbol{b}} \text { (fraction) }\end{array}$ & $\begin{array}{c}\text { Rock Charge } \\
\boldsymbol{J}_{\boldsymbol{r}} \text { (fraction) }\end{array}$ \\
\hline $1997 / 10 / 0810: 29$ & 182 & 2666 & 0.25 & 0.11 & 0.14 \\
\hline $1997 / 10 / 0900: 23$ & 175 & 2415 & 0.27 & 0.07 & 0.20 \\
\hline $1997 / 10 / 1019: 25$ & 186 & 2974 & 0.19 & 0.16 & 0.03 \\
\hline
\end{tabular}

The three sets of operating conditions are plotted on Figure 11 and form an operating curve in the ( $J_{b}, J_{t}$, Powerdraw - Weight ) space. The powerdraw and weight contours are plotted in this space also and now form intersecting powerdraw and weight surfaces, respectively. 


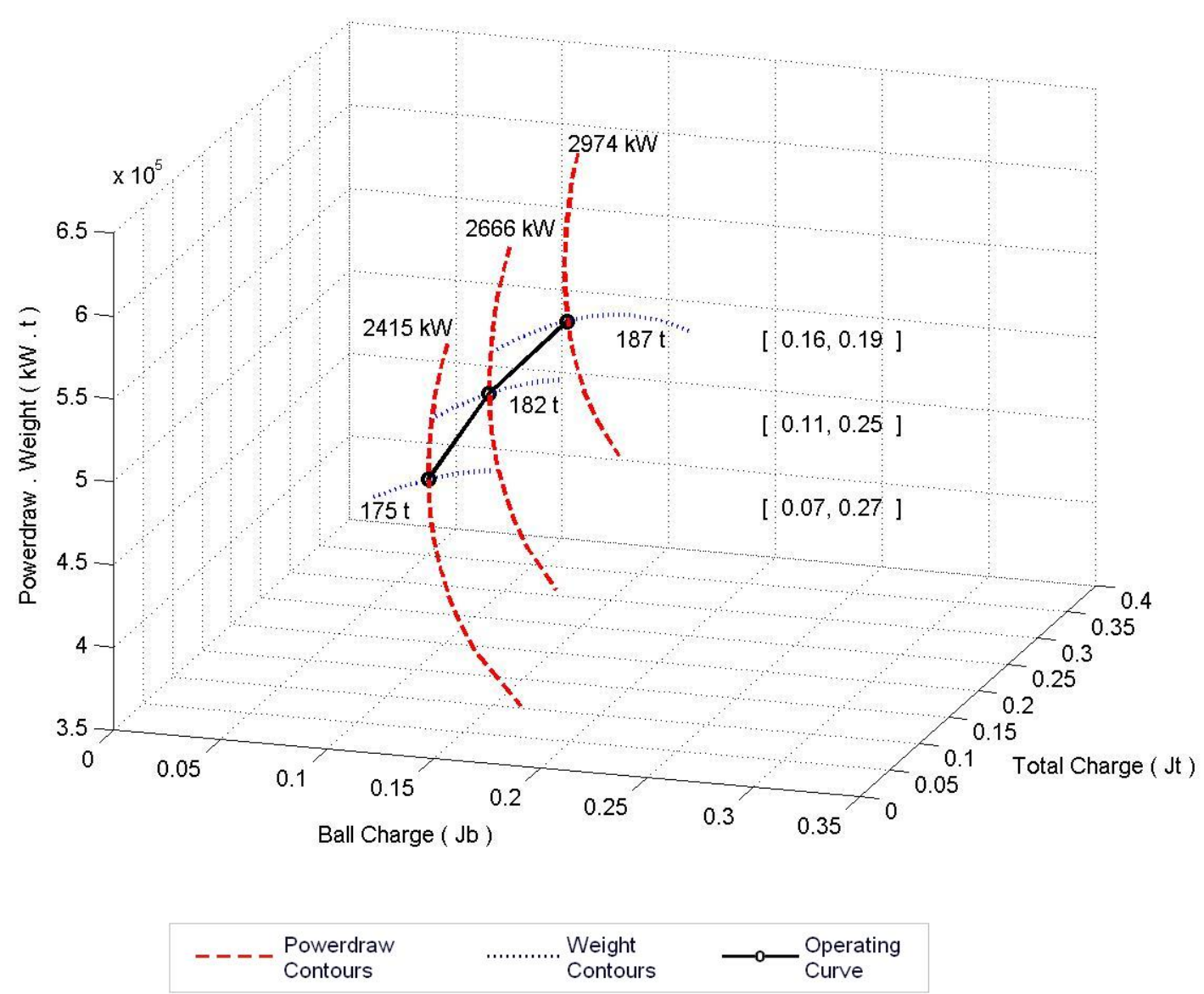

Fig.11 SAG mill operating curve, Powerdraw contours \& Weight contours in the $J_{b}-J_{t}-$ Powerdraw $•$ Weight space

Taking a position normal to the ball charge fraction - total charge fraction plane and plotting the controlaction contours results in Figure 12, which is another version of Figure 10 with more contours shown. The three operating conditions that make the operating curve did not occur in a left-to-right sequence. The central point is the first set of conditions in time, the left-most point is the second and the right-most point is the third.

Moving from the central point to the left point would require decreases in feedrate and ball addition. The time between these two conditions is approximately 14 hours. To achieve the second set of conditions, the controller would have made multiple moves in feedrate and ball addition (in contrast to one large decrease in feedrate and one large decrease in ball addition rate). One can imagine these moves as a saw-tooth profile moving right-toleft, above the operating curve from the central point to the left point. The segments that make up the saw-tooth would be parallel to the control-action contours.

Moving the operating conditions from the left-most point to the right-most point, the controller moves would make a saw-tooth profile moving left-to-right, below the operating curve (increases in ball addition and increases in feedrate). The time between these two conditions is approximately 43 hours. 


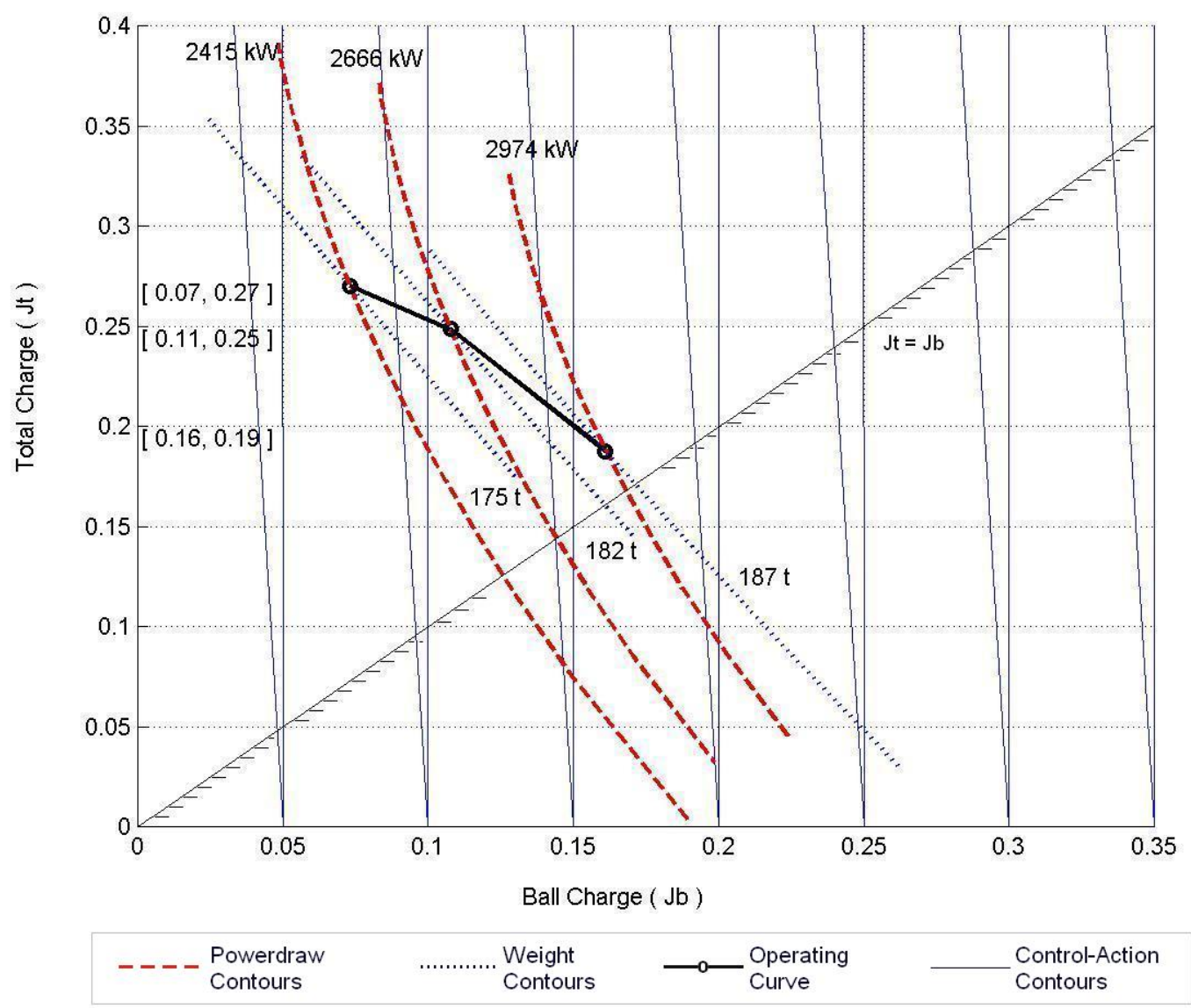

Fig.12 SAG mill operating curve, Powerdraw contours, Weight contours and Control-Action contours in the $J_{b}-J_{t}$ space

It is not possible to validate the proposed controller moves against the actual process since:

1. The controller and process it controls are simulations.

2. The controller assumes the SAG mill is a purely integrating vessel. Whilst this is true overall, there is also some first-order plus dead time behaviour exhibited by the real plant, particularly for the rock (and total) charge, that this simplification does not capture.

3. The simulation occurs over a time frame of minutes rather than hours

4. SAG mill ball addition (SMBA) does not exist as a manipulated variable in the real plant. Grinding balls are batch-fed to the mill as dictated by the operator.

However, the following points illustrate that overall the controller moves would have been consistent with what actually took place in the plant:

Central-to-Left-most Point: During the 14-hour period there was no ball charging (effectively a ball addition decrease) and the weighted-average of the nine (9) feedrate changes is $-25 \mathrm{t} / \mathrm{hr}$ (a feedrate decrease). Decreases in feedrate and ball addition are consistent with the proposed control-actions above.

Left-most-to-Right-most Point: During the 43-hour period three batches of grinding balls were charged to the mill (a ball addition increase) and the weighted-average of the forty (40) feedrate changes is $+95 \mathrm{t} / \mathrm{hr}$ (a feedrate increase). Increases in feedrate and ball addition are consistent with the proposed control-actions above. 


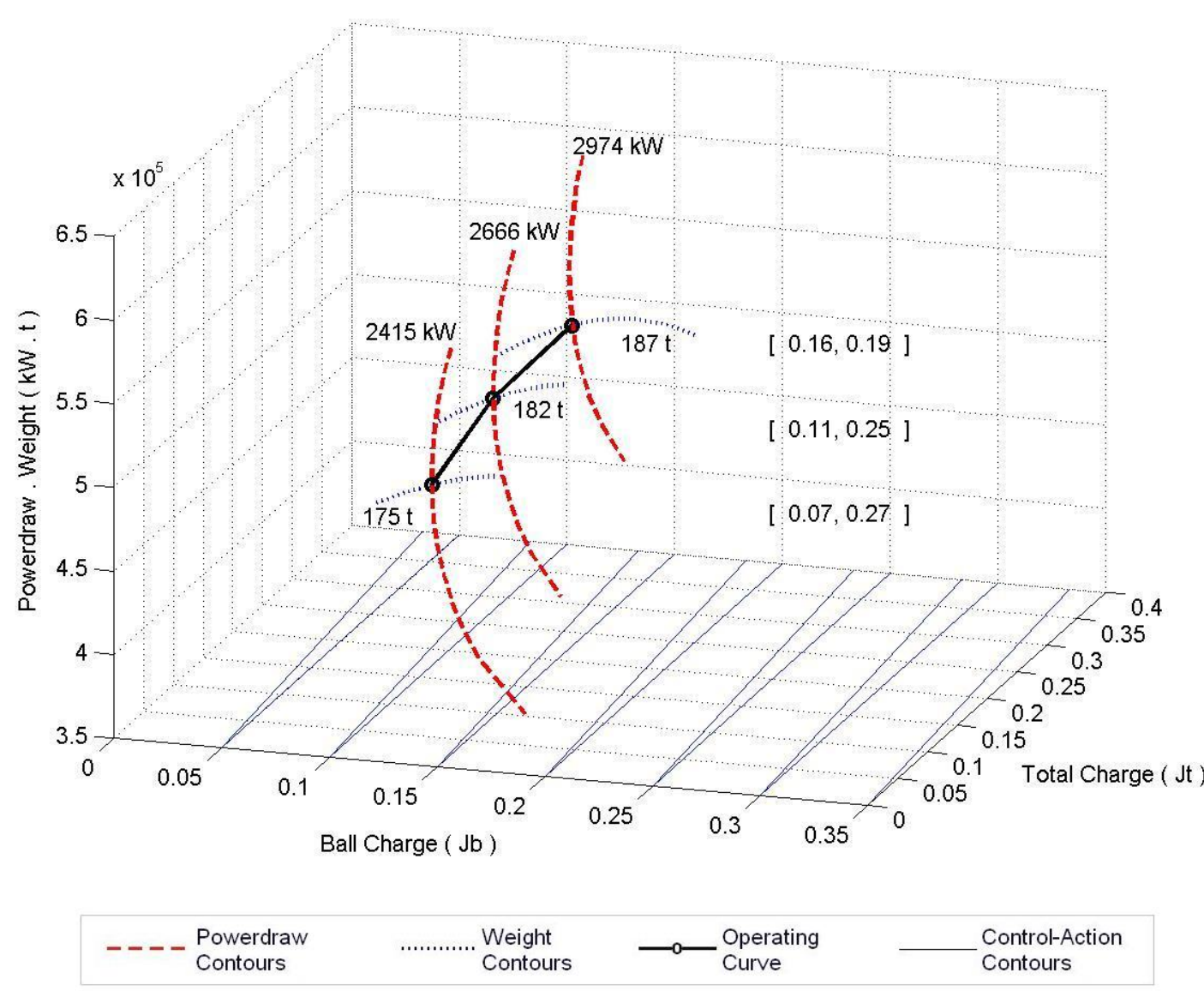

Fig.13 SAG mill operating curve, Powerdraw contours, Weight contours and Control- Action contours in the $J_{b}-J_{t}-$ Powerdraw $\cdot$ Weight space

Placement of the operating curve, along with the mill weight and powerdraw contours, in the $\left(J_{b}, J_{t}\right.$, Powerdraw - Weight) space eases visualisation of the interrelations of the mill charge fractions and powerdraw and weight measurements. Super-imposing control-action contours of the MPC controller developed above has furthered the understanding of how control actions could move the process along the operating curve.

The investigation of control actions of a real controller in relation to the operating curve is a possible avenue to progress research in this area.

\section{CONCLUSIONS AND RECOMMENDATIONS}

A case study application of inferential measurement models for semiautogenous grinding (SAG) mills developed and presented in earlier papers has been investigated here.

To place the utilisation of the inferential measurement models developed in this research into context, a multivariable model predictive (MPC) controller simulation was developed. A series of first-order plus dead-time (FOPDT) models were developed from plant data for the simulation. However, since the behaviour of the FOPDT model simulation was not completely satisfactory, rate-of-change (ROC), integrator models, were developed as an alternative. 
The MPC controller simulation is utilised to investigate a SAG mill charge control strategy, with the inferential measurement models as setpoint and constraint control variables. The $M P C$ controller performance was compared to that of a PID control simulation of powerdraw control and found to be superior.

Control-action contours of the $M P C$ controller were super-imposed on the mill weight and powerdraw estimate contours on the total charge - ball charge plane. An operating curve is generated from selected plant conditions. Creating a combined-variable (powerdraw - weight) allowed the projection and visualisation of the operating curve and estimate contours in a three dimensional space. The operating curve was discussed in terms of possible utilisation by the $M P C$ controller and the control-action moves with encouraging results.

The real-plant utilisation of the inferential measurement models in a $M P C$ controller, the operating curve and the dependence of the operating curve on ore hardness are possible avenues for future research.

\section{NOTE}

Since the first paper (Apelt et al., 2001a) and investigative report (Romagnoli et al., 1997), the process control team at Northparkes Mines have upgraded the PLC controllers in the grinding circuit. The increased capabilities allowed the site to commission the implementation of mill load constraint-control (Thornton et al., 2005). The control strategy employs a pair of microphones for the audio-indication of charge toe position, manipulating feedrate to control charge level subject to an upper constraint on mill powerdraw. The SAG mill control system has a high degree of operator acceptance (95\% utilisation) and can deal with "a wide range of plant disturbances and keep the mill operating at optimal load."

\section{ACKNOWELDGEMENTS}

Acknowledgements go to Northparkes Mines for their assistance with and permission to publish circuit information, the Centre for Process Systems Engineering for significant hosting and the University of Sydney for providing Australian Postgraduate Award funding for this research.

\section{REFERENCES}

Apelt, T.A. (2007). Inferential Measurement Models for Semi-autogenous Grinding Mills. PhD thesis. Department of Chemical Engineering, University of Sydney, Australia. See http://www.geocities.com/thomasapelt.

Apelt, T.A., S.P. Asprey and N.F Thornhill (2001a). Inferential measurement of SAG mill parameters. Minerals Engineering 14(6), 575 - 591.

Apelt, T.A., S.P. Asprey and N.F. Thornhill (2001b). SAG mill discharge measurement model for combined state and parameter estimation. In: SAG 2001. Vol. IV. UBC. Vancouver, B.C., Canada. pp. 138-149. Third international conference on: Autogenous and Semiautogenous Grinding Technology.

Apelt, T.A., S.P. Asprey and N.F Thornhill (2002a). Inferential measurement of SAG mill parameters II: state estimation. Minerals Engineering 15(12), 1043 - 1053.

Apelt, T.A., S.P. Asprey and N.F Thornhill (2002b). Inferential measurement of SAG mill parameters III: inferential models. Minerals Engineering 15(12), 1055 - 1071.

Apelt, T.A. and N.F Thornhill (In Press). Inferential measurement of SAG mill parameters IV: inferential model validation. Minerals Engineering.

Chen, X.-s., J.-y. Zhai, S.-h. Li and Q. Li (2007). Application of model predictive control in ball mill grinding circuit. Minerals Engineering 20(11), 1099 - 1108.

Freeman, N., P. Feltoe and D. Nicoli (2000). The Improvements in Control of the Mill 3 Circuit at Alcoa's Wagerup Re nery. In: Seventh Mill Operators' Conference. Australasian Institute of Mining and 
Metallurgy. Kalgoorlie, WA, Australia. pp. 303 - 310.

Fuenzalida, R., E. Cubillos and J. Sepulveda (1996). Plant Experiences on Expert Supervisor Control of Semiautogenous Grinding Circuits. In: SAG 1996. Vol. 2. UBC. Vancouver, B.C., Canada. pp. $642-$ 656. Second international conference on: Autogenous and Semiautogenous Grinding Technology.

Ivezič, D.D. and T.B. Petrovič (2003). New approach to milling circuit control - robust inverse Nyquist array design. International Journal of Mineral Processing 70, 171-182.

Radhakrishnan, V.R. (1999). Model based supervisory control of a ball mill grinding circuit. Journal of Process Control 9, 194-211.

Ramasamy, M., S. Narayanan and Ch.H.P. Rao (2005). Control of ball mill grinding circuit using model predictive control scheme. Journal of Process Control 15, 273-283.

Romagnoli, J. A., O. Galan and T. A. Apelt (1997). Preliminary Study of SAG Mill Control at Northparkes Mines. Technical report. ICI Laboratory for Process Systems Engineering. Dept of Chemical Eng, University of Sydney NSW Australia.

Thornton, A.J., T. Pethybridge, T. Rivett and R. Dunn (2005). SAG Mill Control at Northparkes Mines (Not So Hard After All). www.mipac.com.au. 